\title{
Organizational and technological aspects of a forensic construction and technical expertise
}

\author{
Inna Zilberova ${ }^{1}$, Vadim Mailyan ${ }^{2}$, and Irina Novoselova $^{1 *}$ \\ ${ }^{1}$ Don State Technical University, 344000, Rostov-on-Don, Russia \\ ${ }^{2}$ Southern Federal University, 344006, Rostov-on-Don, Russia
}

\begin{abstract}
Construction industry development has both positive aspects of a social and economic nature and negative ones, associated with an increase in the number of accidents, poor construction and installation work quality and the emergence of disputes between the participants in construction production. The resolution of conflict situations arising in the construction industry between business entities is possible with the use of special construction and technical knowledge. One of the most demanded application forms of such knowledge is judicial construction and technical expertise.
\end{abstract}

\section{Introduction}

The reason for the investigation within the framework of the forensic construction and technical expertise (FCTE) in many cases, are the events that caused an emergency or the appearance of defects in building objects, as well as in their elements [1]. FCTE at the same time is appointed for the purpose of obtaining the opinion of a construction expert on the issues that directly affect the establishment of the unvarnished truth for the case and making the correct decision. Being a rather lengthy process, forensic expertise includes the following procedures: the appointment of an expertise, the conduct of research and, in some cases, the conclusion assessment [2].

In practice, there are a variety of forensic situations. One of the most common is a forensic situation arising from the changes in the characteristics of a construction or reconstruction object that violate the terms of the contract [3]. This forensic situation, as a rule, is the result of a dispute between the customer and the contractor regarding the types, volumes, quality and cost of construction or repair and restoration work performed.

Industrial relations between the customer and the contractor are regulated by the Civil Code of the Russian Federation, as well as by the system of normative and technical documents, the structure and content of which are presented in the Federal Law "On Technical Regulation" dated 27.12.2002 No. 184-FL.

\footnotetext{
${ }^{*}$ Corresponding author: irina1000000@gmail.com
} 


\section{Research materials and methods}

The subject of judicial evidence is the complete or partial failure of the parties to fulfill their obligations under the contract. The subject of dispute in this situation is the parameters of quantitative (volumes and types of construction and installation work, materials and products of repair and construction production, provided by the contract agreement and the technology for their implementation in accordance with regulatory documentation in construction), qualitative (properties of products of repair and construction production: functional, operational, consumer, aesthetic, safety, etc.) and cost nature (the cost of construction and installation work performed according to the contract, as well as materials used in the work process) $[4,5,6]$.

In order to resolve forensic situations, it is necessary to carry out a number of interrelated studies that represent a single system, the task of which is to prepare the answers to the questions asked by the court [7]. Expert research can be preceded or accompanied by additional or auxiliary research, which can be used, including as the initial data in the expert work course [8].

The studies on the determination of the volume, quality and cost of construction or repair and restoration work performed can be presented in the form of interdependent stages, different in content, but implying the consistent use of certain techniques and methods, as well as technical means.

The methodology for conducting an expert study on the question raised by the court should be based on an integrated approach and includes the following stages:

Stage 1 - analysis of documents submitted for the research:

- analysis of the initial data specified in the request for a construction and technical study;

- analysis of the question posed for resolution;

- identification of documents that are necessary for the research part and on the basis of which it is possible to conduct the research on the question posed;

- the choice of one or another method of conducting the research (field expertise of the object, the degree of detail of the expertise and the type of office processing - calculations, diagrams, description, comparison) depending on the tasks, taking into account the question posed for resolution;

- selection and study of normative, technical, reference literature;

- drawing up a program for a field survey.

2nd stage - full-scale expertise of the research object:

- fixation of the research object by drawing up sketches and diagrams by hand, for fixing measurements and data during expertise;

- photographic recording of the research object;

- measurements of the research object;

- inspection of the object by performing local, limited in area disclosures, made to solve a clearly posed research task (if necessary);

- fixation of field survey data.

3rd stage - conducting research on the question posed on the basis of field survey data and office processing of the results obtained:

- processing and analysis of field survey materials with their transfer to a standard format: drawing up diagrams, text descriptions;

- analysis of photographic materials by transferring them into the format required for insertion into the text;

- analysis and comparison of the field survey results with the materials submitted for the study;

- analysis and comparison of field survey results and research results of the materials submitted for research with the data from regulatory and technical literature; 
- fixing the results of comparative analytical work by describing, formulating intermediate conclusions;

- generalization of all information obtained during the construction and technical research, drawing up a conclusion containing conclusions that give an exhaustive answer to the question posed.

From an organizational and technological point of view, the presented complex of studies can be characterized as follows:

- the predominance of linear technological communication, reflecting the sequence of performing individual operations within the research stages;

- the cyclical nature of the technological connection, due to the return to the passed stages, the repetition of the previously performed actions with the conduct of more detailed studies in order to increase the reliability of the results obtained;

- possibility of parallel research execution;

- the use of adaptive technology, which makes it possible to adjust the sequence of performing individual operations and actions during each stage of the study.

The need to assess the conclusion, interrogate an expert and consider the appointment of a repeated or additional expertise - appears when there are suspicions of bias and prejudice of the expert, poor-quality research or giving a false or erroneous conclusion. In this case, the expertise admissibility issue as an evidence is considered. If the court recognizes the expert opinion as inadmissible evidence, it becomes possible to appoint a new study by another expert.

The general procedure and technical standards for determining the scope of work performed are presented in specialized literature and thematic reference books [9].

\section{Results and Discussion}

Expert activity is not a balanced system. It is a fairly dynamic and changeable process, which is a movement from some forms of activities organization of others, more modern and accurate, which imposes certain requirements on the knowledge, skills and experience of experts.

Professional knowledge of an expert-builder, their volume and structure are determined by the content of the questions posed by the court to the expert or specialist, which, in turn, are formed by the emerging forensic expert situations.

The scientific and methodological apparatus of a forensic expert-builder must meet modern requirements [10]. Various data sources are used in the construction and technical expertise:

1. Methodological recommendations of the Ministry of Justice of Russia and forensic experts, which represent a generalized practical experience in resolving the most common expert situations.

2. Building codes and regulations, state standards, technical instructions and regulations, as well as other regulatory and technical sources, which present the generalized result of the implementation of scientific provisions in practice.

3. Own database, consisting of special literature, provisions of a regulatory and technical nature, special knowledge about the subject of expertise.

It is impossible to provide the necessary completeness of information necessary for the effective work of a forensic expert-builder without the use of modern information technologies.

The active development, improvement and integration of information technologies currently make them attractive, including for expert activities, in particular FCTE. In the modern world, technologies occupy a special place in the dissemination of information and are an effective tool in the hands of a person, contributing to obtaining a more effective 
result in a particular area of work [11]. However, not in all spheres of activity, information support has reached a sufficiently high level to meet the needs of specialists in the information required at a given moment. In the work of a forensic civil engineer expert, it is of great importance how quickly he receives the necessary and relevant information. The difficulty lies in the fact that a huge amount of information accumulated over a long period of time is stored in a disordered form in separate specialized institutions, which in turn makes it difficult to translate this information into electronic form. Thus, the experts do not have real-time access to this information.

Insufficient optimization of information support for the forensic construction experts' activities leads to an increase in the FCTE timing, as well as can negatively affect the quality of the results obtained during the study. Optimization of information support for construction and technical expertise through the use of the latest generation software will allow solving a large number of routine and repetitive processes at high speed, which in turn will significantly increase the forensic civil engineer experts' work efficiency.

The introduction of information technologies into the process of construction and technical expertise will make it possible to more effectively carry out work in this area [12]. However, it should be borne in mind that such an information system may store information that the expert does not need for a long time, but at any time there may be a need for prompt access to them. Such a principle in FCTE is referred to as "advancing information supply" or "advancing information demand" by the experts. He is obliged to meet the existing needs of expert builders, as well as those to predict the appearance of new ones. Thus, from this principle follows another principle of relevance used in the work of information, which is important in this field of activity. The basis of this principle is that the information system should contain information that is relevant at the time of the work of a forensic expert, as well as be regularly updated [13]. It is necessary to continuously update the data on existing regulatory, technical, economic requirements and rules, as well as information on all stages of the research object's life cycle.

A significant amount of data can be disorienting if the user does not have sufficient experience to make it possible, when familiarizing himself with the questions posed to him and the circumstances of the case, to decide what kind of scientific, technical and special information he needs to solve a certain problem [14]. In addition, often in practice, even experienced forensic construction experts have a need for prompt access to the base of standard conclusions, as well as the results of expertise conducted in other regions of the country or even in other states, taking into account the specifics of the issue under study. The solution to this problem will optimize the work of specialists in the FCTE field.

Nevertheless, the implementation of information technology in the work of forensic civil engineer experts is negatively influenced by the reasons of a subjective nature. A highly qualified construction expert may have the skills to carry out a large volume and range of construction and technical expertise. But since the sphere FCTE insufficiently informatized, this can cause a significant decrease in the rate of implementation of information directly into practice.

Currently, construction and technical expertise is developing in a wide range of areas, and due to objective reasons, one expert cannot master each of them [15]. Specializing in a particular area, an expert gets the opportunity to master it perfectly. At the same time, such a differentiation of scientific knowledge is not strict, and an expert who has mastered one of the areas to perfection can begin to study the related ones, which, however, does not always work out due to the fact that the information is constantly updated and continuous professional development in the chosen area of knowledge is necessary.

Forensic experts have a high workload and a small amount of time to master all the software systems they need in their work. In order to get at least the initial skills of work and really reduce the time for the expertise, it is necessary to spend a significant amount of 
effort. At the same time, there are analogues of the existing information systems, to work with which some training is required. All these moments create the barriers that prevent the effective use of information support by a modern forensic construction expert in conducting the research within the framework of FCTE. In the future, it is important to pay more attention to the issues related to the development of specialized programs for forensic civil engineer experts, and in particular, the development of new and easy-to-use software systems for information support to optimize work in this area.

\section{Conclusion}

The specialized knowledge of an expert builder is characterized by the structure complexity and a wide range of content diversity. Moreover, each type of research has its own unique and specific features, which determines the need for an individual cognitive approach to resolving each expert situation. The process effectiveness of forensic expert understanding is manifested in the optimization and increase of the technology efficiency as well as the detailing of the conducted research, reflected in the description of its progress and results in the expert opinion.

\section{References}

1. S. G. Sheina, L. V. Girya, E. V. Vinogradova, A. Sobolevskiy, IOP Conference Series: Materials Science and Engineering 913, 042032 (2020)

2. I. Y. Zilberova, Materials Science Forum 931, 834-839 (2018)

3. S. Barkalov, P. Kurochka, A. Khodunov, N. Kalinina, E3S Web of Conferences 164, 08030 (2019)

4. S. Sheina, L. Girya, MATEC Web of Conferences 129, 05020 (2017).

5. S. L. Pushenko, Y. V. Staseva, M. V. Kvitkina, IOP Conference Series: Materials Science and Engineering, 1001, 012115 (2020).

6. E. V. Puchkov, N. A. Osadchaya, A. D. Murzin, Journal of Advanced Research in Law and Economics 9, 615-624 (2018).

7. I. Y. Zilberova, V. D. Mailyan, A. L. Mailyan, IOP Conference Series: Materials Science and Engineering 698, 022085 (2019).

8. V. Y. Mishchenko, Y. D. Sergeev, A. Y. Sergeeva, V. Y. Myasischev, R. Y. Myasischev, IOP Conference Series: Materials Science and Engineering 972, 012063 (2020).

9. A. Mailyan, E. Korol, R. Petrosyan, D. Antoniadi, IOP Conference Series: Materials Science and Engineering 896, 012052 (2020).

10. O. V. Kluchnikova, O. A. Fil, AIP Conference Proceedings 2188, 060003 (2019).

11. L. Zelentsov, K. Krukov, D. Pirko, M. Shogenov, IOP Conference Series: Materials Science and Engineering 753, 042022 (2020).

12. N. Ivannikova, P. Sadchikov, A. Zholobov, Studies in Systems, Decision and Control 199, 634-645 (2019).

13. S. Sheina, V. Belash, V. Ulianskaia, E3S Web of Conferences 110, 01054 (2019).

14. L. Panasyuk, G. Kravchenko, E. Trufanova, MATEC Web of Conferences 106, 02027 (2017).

15. T. Poliakova, M. Grigoryan, MATEC Web of Conferences 196, 02014 (2018). 